\title{
MODELLING OF TRAFFIC POLICY MEASURES FOR AMBIENT AIR QUALITY MANAGEMENT

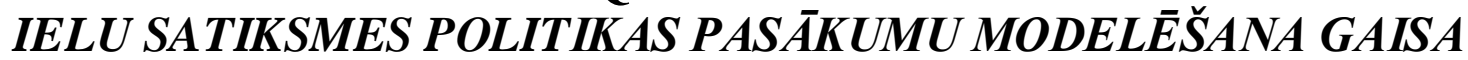

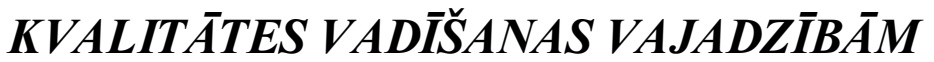 \\ LINAS KLIUČININKAS, SIMONA BALKEVIČIENĖ, JOLITA MOCKUVIENE்
}

\author{
Kaunas University of Technology, Department for Evironmental Engineering, \\ Radvilènų 19, 50254 Kaunas, Lithuania, \\ Phone: +370 37351008, fax: +370 373000152, \\ e-mail:linas.kliucininkas@ktu.lt; jozaik@ktu.lt
}

\begin{abstract}
This paper presents the application of the Integrated Transport Effect Modeling System ITEMS, taking into consideration existing vehicle fleet, traffic flows, and ambient air quality monitoring data. The objective of this study is to estimate the exhausts of $\mathrm{CO}, \mathrm{NOx}$, and $\mathrm{SO}_{2}$ released by motor vehicles in relation to predictive traffic policy measures in Kaunas, Lithuania.

This study analyses the extent to which some traffic policies and future trends may influence the ambient air pollution in urban environment. Three traffic policy measures such as: i) increase of car parking fee; ii) reduction of car parking places; iii) introduction of dedicated traffic lines for public transport are considered as the case studies to examine the extend to which they could reduce emissions from motor vehicles. At the same time, each policy measure comprises four scenarios including one, which indicates the current situation. The comparative analyses of the influence of different traffic policy measures on vehicle/passenger kilometres travelled and on emissions are presented.
\end{abstract}

Keywords: ambient air quality, ITEMS, traffic modelling, transport policies, urban transport.

\section{Introduction}

Cities notably experience increasing signs of environmental stress in the form of poor air quality. Automobile transport is now an inherent part of our civilisation and, as has happened with many other technological advancements, the negative aspects are becoming more and more pronounced. A vast majority of the urban population is exposed to conditions that exceed air quality guidelines established by the World Health Organization [1]. The use of automobiles has strongly increased during the last few decades. The number of passenger kilometres by private car per capita increased by $90 \%$ in Western Europe [2]. The number of motorized vehicles in the world grew by about 600 million between 1950 and 1990. Of the 675 million motorized vehicles in 1990, approximately 80\% were for passenger transport [3]. In Western Europe motor vehicles have overtaken industrial processes in the combustion of coal as the major source of theair pollutants.

As motor vehicle traffic is projected to increase considerably, transport-related emissions are also expected to rise, exacerbating air quality problems. The problems appear even despite the increasing use of abatement measures. The introduction of catalytic converters is not sufficiently effective in urban areas where travel distances are too short to warm up the converter. Moreover, a substantial part of the pollutants originates from heavy vehicles, for which no effective cleaning technology is yet available. Air pollution from traffic, particularly in street canyons as well as in urban areas, is still a major issue of the environmental policy.

This continual traffic growth raises concerns over the impact of traffic emissions on human health and urban environmental quality. It fuels the demand for a coherent regulatory framework for the management of traffic, air quality, and emissions at local and regional scales.

Transport policies can have significant impacts on the environment. Solving any problem of transport impacts one should consider the management issues of transport and traffic systems as well. The sustainable growth respecting the environment is one of the main objectives of the Common Transport Policy [4]. The new urban policy emphasizing a compact urban structure 
with mixed use, with high urban planning, and ecological qualities need to provide mobility in a sustainable way. At least the following classical strategies are necessary for this:

- Traffic avoidance: avoidance of increased distances throughout more compact city structures, mixed use and concentration on central locations within a region.

- Shift in the means of transport: a large portion of car traffic can be shifted to public transport, bicycle and pedestrian traffic.

- $\quad$ Slowing down traffic and planning of street space: danger, accidents and noise pollution can be significantly reduced by restricting vehicle speed.

The transport policy approaches towards travel in urban areas remain particularly challenging and now focus on the necessity of integrated strategies which combine the use of urban land and transport planning, as well as the improvement of public transport systems and pricing measures. The main goal of the EU environment and transport policies is the reduction of external costs of transport.

\section{Overvie w of decision support systems for urban transport policies}

For the first time the EU Framework Directive 96/62/EEC and the first Daughter Directive introduce the use of modelling in assessment and management of air quality. The directive recognizes that air quality models are valuable tools for the assessment and forecast of air pollution. They are essential tools in the development of action plans to improve air quality, what is the ultimate goal of Member States and the local authorities in order to fulfil their obligations under the directives. Models improve the effectiveness of the air quality management.

The application of this numerical tool is also important in the traffic management and in the definition of strategies for the air quality management in urban centres, as well as for the development of future traffic scenarios. Another main advantage to be gained from using models in the assessment and management of air quality is that it enhances the ability to map the spatial distribution of pollutant concentrations what is not possible with spatial coverage of air quality measurements. This gives a chance to relax on the measurement requirements (possibility to reduce a number of stations) and thus to produce a more cost-effective and complete air quality assessment. Models are the only available tools if the scenario at the impact of possible future sources or alternative future emissions on air quality is to be investigated.

Currently, there is a number of emission models that differ in the fleet composition (vehicle categories and age), driving patterns (average speed only or instantaneous speed and acceleration), covered pollutants, and types of emissions (hot, cold, or evaporative). The selection of the adequate model is an important step to reduce final uncertainties on air quality prediction [5]. The locations of the air quality assessment are to be sited in places, where the highest concentration, to which the population is likely to be exposed, occurs. An air quality model should focus not only on the urban background, but also on calculating representative values at street level. At traffic oriented sites the assessment point should be representative of the air quality in a surrounding area of at least $200 \mathrm{~m}^{2}$ [6].

\section{The ITEMS model}

The Integrated Transport Effect Modelling System ITEMS consists of various modules that have been designed and tested, resulting in an urban air quality management tool that can provide reliable answers to policy makers and traffic planners. The ITEMS is made out of five models: transport model, economy model, vehicle stock model, energy-emission model, and environment model. These models are inter-related through a central data base from which they extract the input data and where they return their results which can therefore, become inputs of the other models. The model is developed as a cooperative effort of Enerdata S.A. and Grenoble municipality, France.

The ITEMS deals with the urban area only. This includes the centre as well as the closer surroundings of a monocentric city of 100,000 to 800,000 inhabitants. This limitation seems to 
make sense because the most serious traffic problems occur in urban areas and not within regional areas. Metropoles have a multicentric structure that requires a specific modelling approach [7].

To keep the modelling system simple and to make it easier to transfer the ITEMS to other urban areas, only three different areas are distinguished: the city centre, the rest of the urban area and the suburbs. No networks are considered with the exception the only link between the three zones.

From environmental point of view, the most important is an energy-emission model, which calculates energy consumption and pollutants emissions due to the traffic of various vehicles. It is an engineering type model which takes into account the different technical influences acting upon energy efficiency and emissions of pollutants, for example:

- cold start

- driving behaviour

- $\quad$ age of vehicles

- $\quad$ technologies of vehicles and engines

- $\quad$ legislation on fuels and emissions

- maintenance programme.

An energy-emission model considers the following pollutants: $\mathrm{CO}_{2}, \mathrm{CO}, \mathrm{HC}, \mathrm{NOx}, \mathrm{SOx}$, particulate matter, VOC.

\section{The street traffic flows in Kaunas}

Kaunas, the second major city of Lithuania, is situated in the central part of the country. The administrative area of the city makes up $157.15 \mathrm{~km}^{2}$ and the number of inhabitants is approaching 400.000. Rapidly growing number of individual cars is identified as a major contributor to the ambient air pollution, especially, in the central part of the city. The authors divide the city area into three traffic zones according to the estimates of traffic flows and the character of the built-up areas (see Fig.1).

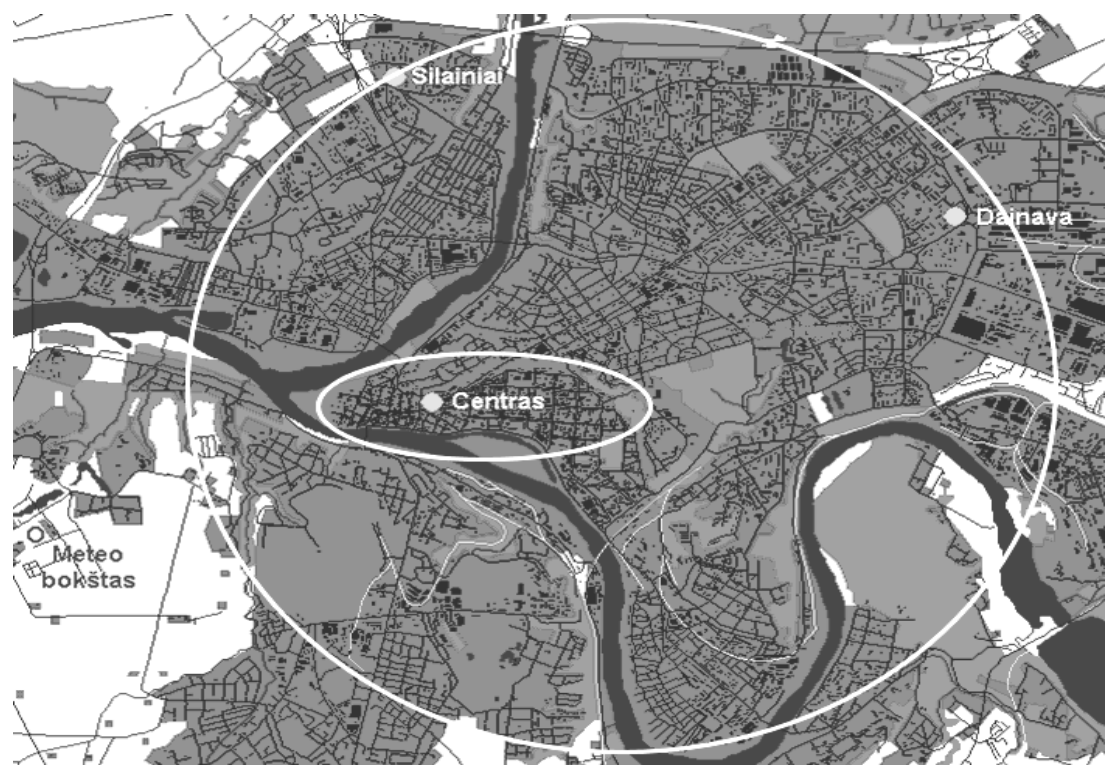

Fig. 1. Defined traffic zones in Kaunas

The analysis of the street traffic flows is based on the manual counts carried out during the years 1999 and 2000, as well as the automated traffic flows analysis, performed by Transport and Road Research Institute (TKTI, Lithuania) during the period June-November 2001 [8]. The study from 2001 involves measurements of traffic intensity, compositions of flows, and vehicle speed.

The analysis of the data sets for 2001 reveals that the average traffic intensity (ATI) for the central part of Kaunas city, based on 24-hour time series with the exceptional case of summer vacations, is rather stable during the whole year. The analysis of the street traffic flows in respect 
to the driving speed shows that characteristic speed for the central part of the city ranges between 40-60 km/h. The stationary counter-classifier Marksman 660 (Golden River Traffic, United Kingdom) was used to identify 24-hour yearly flow averages in the different vehicle classification groups. Periodical traffic flow intensity measurements were carried out during one week each month in the period of June - November, 2001. The measurements estimate: a) annual averages of traffic intensity during 24-hours, b) variation of traffic intensity averages during 6 month, c) 24-hour traffic intensity for each day of the week, d) character of traffic intensity fluctuations during 24 hours, e) average speed of traffic flow.

Table 1 presents monthly and yearly 24-hour traffic intensity averages and ratios between monthly and yearly averages. The averages of weekly measurements serve as monthly averages of appropriate month. The authors distinguish that 'commuting circle' reflects temporal variations of traffic flows fairly well and is rather stable all over the year. It is taken into consideration was considered that meteorological conditions during winter and early spring have essential influence on urban traffic flows and have strong correlation with traffic flows intensity on the out of town roads. As a result, monthly urban traffic flows averages during January April are estimated in comparison to the traffic flow intensity on the out of town roads.

Table 1.

Monthly and yearly 24-hours traffic intensity averages Donelaicio str. (The central part of the city)

\begin{tabular}{|c|c|c|c|c|c|c|c|c|c|c|c|c|}
\hline \multirow{2}{*}{$\begin{array}{l}\text { Yearly } \\
\text { 24hours } \\
\text { average }\end{array}$} & \multicolumn{12}{|c|}{ Month } \\
\hline & 1 & 2 & 3 & 4 & 5 & 6 & 7 & 8 & 9 & 10 & 11 & 12 \\
\hline & \multicolumn{12}{|c|}{24 hours monthly average (vehicles / 24hours) and ratios between monthly and yearly averages (\%) } \\
\hline 12800 & 9900 & 10600 & 11600 & 12900 & 13700 & 13700 & 12600 & 12200 & 13900 & 14100 & 14200 & 14200 \\
\hline & 0.77 & 0.83 & 0.91 & 1.01 & 1.07 & 1.07 & 0.98 & 0.95 & 1.09 & 1.10 & 1.11 & 1.11 \\
\hline
\end{tabular}

Table 2.

Traffic intensity averages during weekdays, Donelaicio str. (The central part of the city)

\begin{tabular}{|c|c|c|c|c|c|c|c|c|c|c|c|}
\hline \multirow[t]{3}{*}{ Period } & \multicolumn{3}{|c|}{ Average 24 hours intensity } & \multirow{3}{*}{$\begin{array}{c}\text { Ratio } \\
\text { between } \\
\text { working } \\
\text { and } \\
\text { weekend } \\
\text { days } \\
\end{array}$} & \multicolumn{7}{|c|}{ Week days } \\
\hline & Total & $\begin{array}{c}\text { Working } \\
\text { days }\end{array}$ & $\begin{array}{l}\text { Weekend } \\
\text { days }\end{array}$ & & 1 & 2 & 3 & 4 & 5 & 6 & 7 \\
\hline & & & & & \multicolumn{7}{|c|}{$\begin{array}{c}24 \text { hours yearly averages (vehicles / 24hours) and their ratios } \\
\text { with weekly averages (\%) }\end{array}$} \\
\hline $\begin{array}{c}\text { July- } \\
\text { August }\end{array}$ & 12400 & 14300 & 7700 & 1.86 & 14200 & 14400 & 14100 & 14200 & 14400 & 9200 & 6200 \\
\hline & & & & & 1.149 & 1.167 & 1.139 & 1.144 & 1.162 & 0.740 & 0.500 \\
\hline $\begin{array}{l}\text { September- } \\
\text { November }\end{array}$ & 14100 & 15700 & 10000 & 1.57 & 15300 & 15400 & 15600 & 15600 & 16500 & 12100 & 7900 \\
\hline & & & & & 1.093 & 1.094 & 1.110 & 1.110 & 1.173 & 0.859 & 0.561 \\
\hline
\end{tabular}

Table 2 presents the average intensity of traffic flows during weekdays for the periods JulyAugust and September -November respectively. The maximal values of traffic flows were recorded on Fridays. The differences of the traffic flow intensity from Monday to Thursday ranges within limits of $1.2 \%$. The minimal values of the traffic flows were recorded on Sundays and comprised $60.7 \%$ of week averages. The traffic intensity values for working days exceeded weekend values by 1.44-1.67. This ratio was even more extensive during the period July August.

\section{Modelling transport policy measures}

This section examines the extent to which some transport policy measures can affect local levels of pollutants. Each policy measure comprises four scenarios including one which indicates the current situation. This paper presents modelling results for the central part of the city. The 
analysis is based on the comparison of local air quality from the point of view of different traffic policy measures:

- increase of car parking fee

- reduction of car parking places

- introduction of dedicated traffic lines for public transport

- complex policy measure is considered as alternate combination of three measures mentioned above.

Increase of car parking fee. In late 90's the central part of Kaunas was restricted for the individual car use. To reduce a number of individual transportation in the central part of the city, the municipality of Kaunas has introduced 1 Lt parking fee, which corresponds to 0.29 Euros (scenario a). In order to estimate the extent to which a parking fee could effect transport flows and minimize emissions, the authors have simulate the following hourly parking fees: 2, 3 and 4 Lt (scenarios b, c, d).

Reduction of car parking places. The experience of other European cities shows that the reduction of car parking places can have a significant influence on traffic flows. It reduces transport congestion in the central part of the city, however, it raises parking needs in the precentre zone. The limited number of parking places, well organised public transport, and accessibility by walking motivates visitors' of the city centre for moderate use of individual cars [10].

The authors assume that modelling scenarios will estimate the reduction by 25, 50, 75 \% of car parking places (scenarios b, c, d) in comparison to the current situation (scenario a).

Introduction of dedicated traffic lines for public transport. Dedicated lines for public transport are applied to areas of intensive traffic flows, in particular to central areas of the cities [10]. It provides possibilities of fast mobility for public transport and shortens travelling time, however, at the same time it influences travelling time by car.

In the ITEMS model this alternative measure is expressed in minutes travelled by public transport or car. It is estimated that if dedicated transport lines are not introduced in the centre of Kaunas the same distance will require 7 minutes to travel by car and 17 minutes to travel by public transport (scenario a). The authors elaborate several scenarios for introduction of dedicated traffic lines in the central part of the city:

- $\quad$ shortened travel time by public transport - 15\%, elongated travel time by car - $15 \%$ (scenario b);

- $\quad$ shortened travel time by public transport - 25\%, elongated travel time by car $-25 \%$ (scenario c);

- $\quad$ shortened travel time by public transport - 35\%, elongated travel time by car - 35\% (scenario d).

The validation of the energy-emission model for Kaunas was performed using data series from the stationary monitoring stations Centras, Dainava, and Silainiai (see Fig. 1). The concentration equation from linear source was applied to contemporize modelled amounts of emissions with the monitored NOx, CO, SO2 concentrations [9]:

$$
C(x, y, 0: H)=\left(\frac{2 q}{\sqrt{2 \pi \delta_{z} u}}\right) \exp \left[-\frac{1}{2}\left(\frac{H}{\delta_{z}}\right)^{2}\right]
$$

Under the overcast conditions with an average annual wind speed of $3.37 \mathrm{~m} / \mathrm{s}$, correlations $\delta_{z}$ based on the Pasquil stability class $\mathrm{D}$ was applied to the equation. The linear source strength $q$ for $\mathrm{CO}, \mathrm{NOx}$ and $\mathrm{SO}_{2}$ was calculated and assigned value $q_{\mathrm{CO}}=3.47 \mathrm{~g} / \mathrm{ms}, q_{\mathrm{NOx}}=1.98 \mathrm{~g} / \mathrm{ms}, q_{\mathrm{SO} 2}$ $=0.022 * 10^{-2} \mathrm{~g} / \mathrm{ms}$ respectively. The estimation of ambient air concentration was performed at 10 metres distance from the street and the height of the sampling point was 3.5 metres above the ground level. 


\section{Results and discussion}

The modelling results display changes in total vehicle/passenger kilometres travelled and demonstrate consequent reduction of $\mathrm{CO}, \mathrm{NOx}$ and $\mathrm{SO}_{2}$ emissions. The impacts of different traffic policy measures indicate moderation of kilometres travelled by individual car and increase of passenger kilometres travelled by public transport (buses) [11]. Each measure comprises four scenarios described in the previous section. The average changes are shown in Figure 2.

The minor effect is observed after the increase of parking fee. The taxation has no significant impact on vehicle and passenger kilometres travelled. The 'reduction of parking places' provides better results in comparison to the 'increase of parking fee', however, it is less attractive than the 'introduction of dedicated lines for public transport'. Surprisingly, 'the reduction of car parking places’ gave rather limited increase of passenger kilometres. It is most likely that results are effected by a driver's personal behaviour.

The comparison of individual policy measure has revealed that 'the introduction of dedicated lines for public transport' has major effect on the reduction of emissions from transport. However, the complex implementation of all three measures described will give the most favourable results.

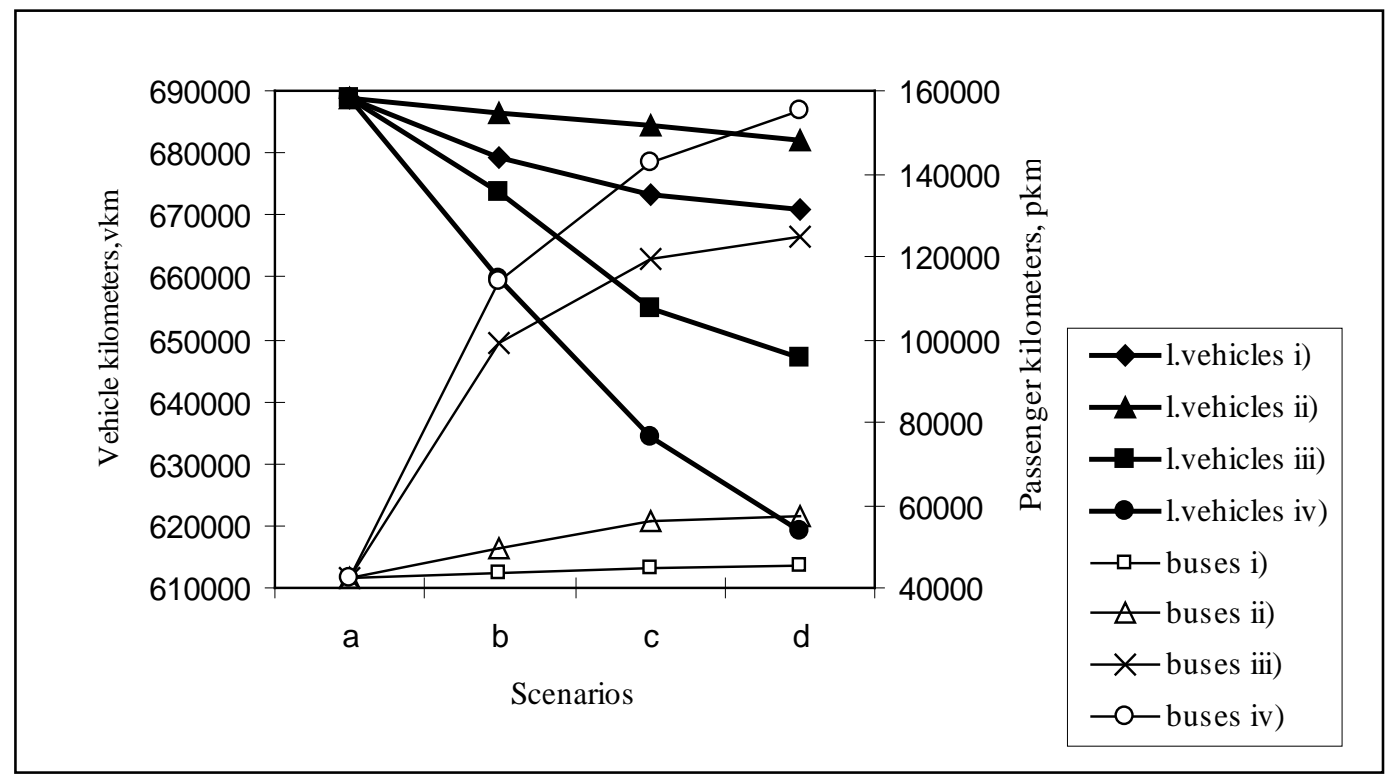

Fig. 2. Estimated traffic flows under different traffic policy measures

Figs. 3-5 show the effects of changes from different traffic policy measures on average levels of the $\mathrm{CO}, \mathrm{NOx}$ and $\mathrm{SO}_{2}$ emissions. The increasing share of passenger kilometres and the decreasing amount of vehicle kilometres produces the evident tendency in the pollution reduction. 


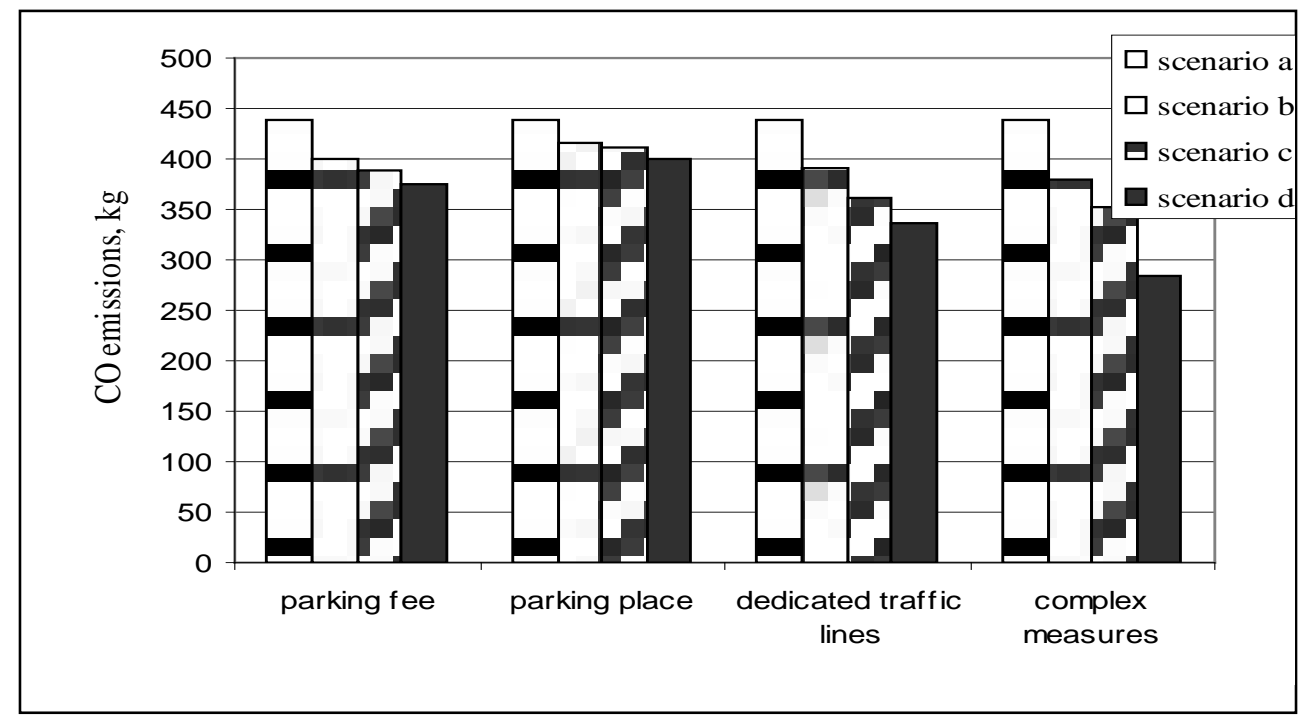

Fig. 3. Estimated levels of CO emissions under different traffic policy scenarios

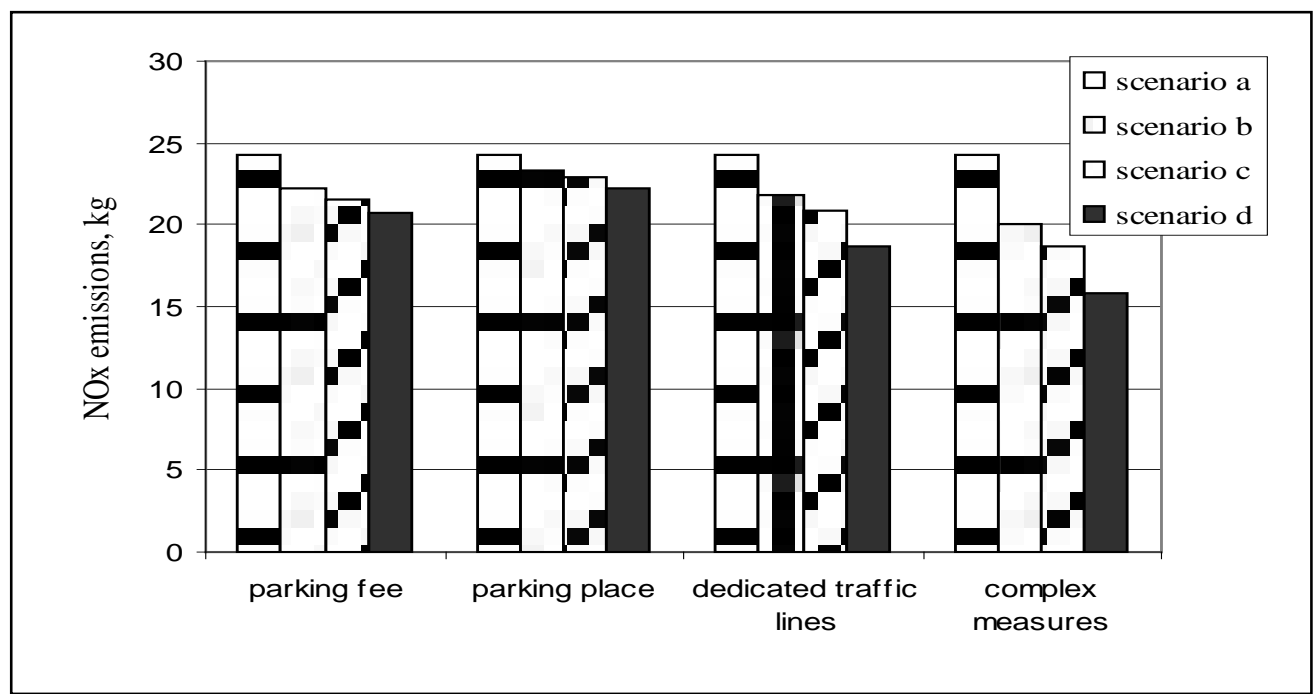

Fig. 4. Estimated levels of NOx emissions under different traffic policy scenarios

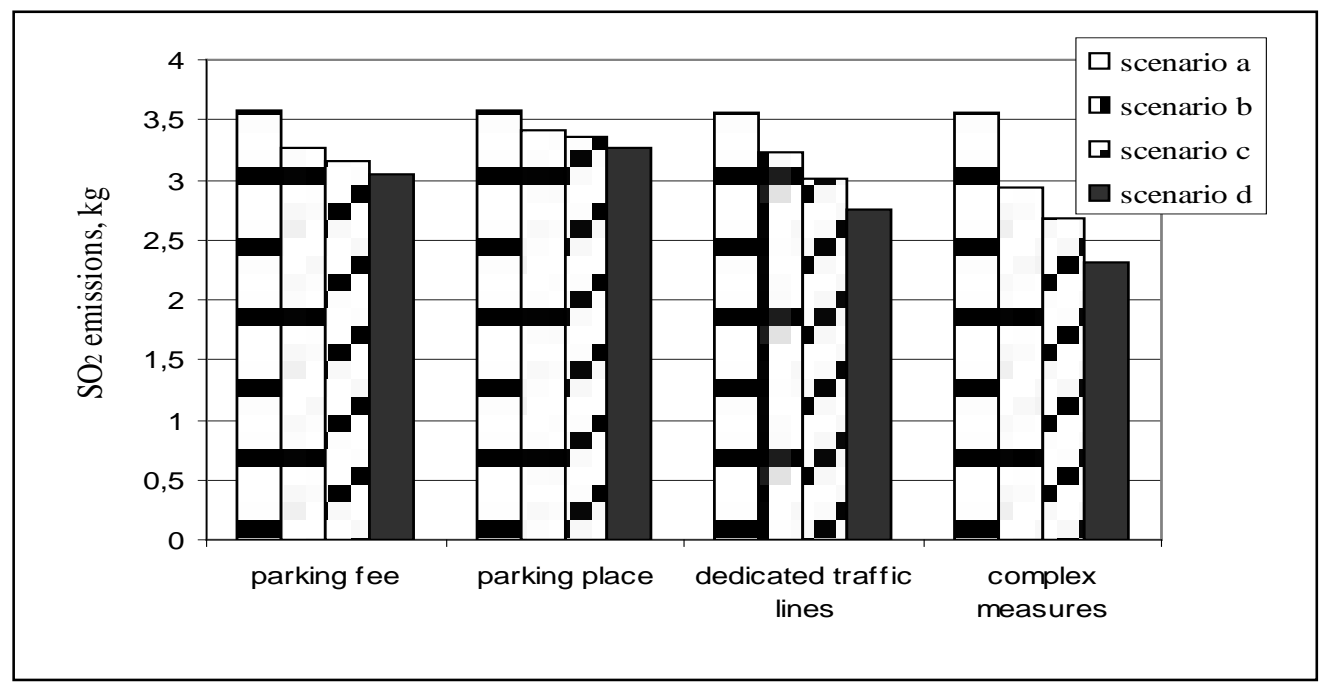

Fig. 5. Estimated levels of $\mathrm{SO}_{2}$ emissions under different traffic policy scenarios 


\section{Conclusions}

The ITEMS modelling system provides analytical possibilities for the implementation of some traffic policy measures in medium size cities. The results of the modelling are specified for Kaunas. However, the general trends found may be applicable in other urban areas under similar conditions as well. Since the policy analyses are carried out comparing the results with the 'current situation' scenario, it gives 'pure' estimates for each policy measure, and eliminates the effects of changes in traffic flows and car fleet.

This paper demonstrates the effects of some transport policy measures and the trends of changes in $\mathrm{CO}, \mathrm{NOx}$, and $\mathrm{SO}_{2}$ emission. The modelling results show that policy measures have varying environmental impacts, particularly for different pollutants. This approach, which provides a range of air pollution indicators from different transport policy measures, is useful in decision making.

\section{References}

1. Europe's Environment: The Second Assessment. European Environmental Agency, Copenhagen: EEA, 1998a.

2. Towards Sustainable Transportation. Paris: OECD Publications, 1996.

3. Adams, J., 1999. The social implications of hyper mobility. In: OECD, Project on sustainable transport (EST). The economic and social implications of sustainable transportation. Proceedings of the Ottawa Workshop, 20-21 October 1998.

4. Meyer M.D., Transport planning for urban areas: a retrospective look and future prospects. Journal of advanced transportation sector, 2000, Vol 34, p. 143-171.

5. Hickman, J., Hassel, D., Jourmard, R., Samaras, Z., Sorenson, S. Methodology for calculating Transport Emissions and Energy Consumption. Luxembourg: European Commission, DG VII, 362pp, ISBN 92-8286785-4, 1999

6. European Community. Council Directive 96/62/EC of 27 September 1996 on ambient air quality assessment and management. Official Journal of the EC L 296,0055-0063, 1996

7. ITEMS - Integrated Transport Effect Modelling System. Tutorial. Enerdata s.a. Grenoble-Gieres, France, 1999.

8. Transporto priemoniu eis mo intensyvumo skaičiavimas automatiniais eis mo intensyvumo skaitikliaisklasifikatoriais. [Traffic intensity measurements using automatic counters-classifiers] Report. Kaunas municipality Environmental Protection Department, P. 93. 2001.

9. Turner, D. B. (1964), 'A diffusion model for an urban area'. Journal of Applied Meteorology.

10. Chiquetto, S., Mackett, R. Modelling the effects of transport policies on air pollution. The Science of the Total Environment, 1995, 169, p. 265-271.

11. Martuzevičius, D., Kliučin inkas, L. Integrated modeling of transport effect in Kaunas city. Proceedings of the International Conference ‘City Environment 2000', Kaunas, Technologija, 2000, p. 82-88. 